\title{
흐르를 European Day of Immunology
}

\section{To the editor:}

Readers of Nature Immunology need not be reminded about the critical involvement of the immune system in many diseases, such as AIDS, tuberculosis, allergies, rheumatism and cancer. Yet the basic immunological mechanisms that mediate these diseases are still incompletely understood. Unfortunately, despite many achievements in basic and clinical immunologic research, the importance of this discipline is often underestimated by the public, including science policy makers and politicians as well as laypeople. To raise public awareness of immunology, the European Federation of Immunological Societies (EFIS) established the Day of Immunology on 29 April 2005. EFIS is the 'umbrella' organization of all European National Immunological Societies, representing 28 member societies with over 17,000 individual members. We coordinated the Day of Immunology and created a website (http://www.dayofimmunology. org/) listing all activities organized by the national societies. Events reported by the participating countries can be found in the 'Event' subdirectories for each country.

A joint press release was prepared highlighting the importance of immunology in basic research and biotechnology (with emphasis on immunotherapeutics and vaccines) as well as in various fields of medicine such as cancer and infectious diseases.
The press release was translated into the 27 languages of the participating societies and was distributed within Europe. Finally, a movie about the devastating consequences of immunodeficiency and modern treatment options for immunodeficient patients was made to illustrate the importance of the immune system. This included interviews with leading European immunologists who emphasized the importance of basic immunology research for the development of new therapies for immune-mediated diseases. The movie was made available to all members of EFIS, and several European television stations broadcast this movie, reaching an estimated 2 million viewers.

National activities were organized by many EFIS members. Many countries, such as Iceland and Italy, put on lectures or symposia covering diverse topics in immunology as a way to bring this discipline to the public eye. France itself organized an incredible 10 lectures across the country. The doors of immunology institutes were opened to the public in Belarus (Minsk, Grodno, Vitebsk and Gomel) as well as in Germany (Magdeburg). An online 'chat room' with a leading immunologist was arranged in Hungary and 'hotlines' were opened to the public in Germany (Berlin). A discussion forum in Berlin that brought together a scientist, a politician, a member of the pharmaceutical industry and an economist was televised and helped to emphasize the need for global vaccination. Interviews with immunologists were published in newspapers and were broadcast by stations all over Europe. Day of Immunology activities also received much retrospective attention in the media, including national TV and radio stations as well as local and national newspapers. In Germany alone, 11 newspaper articles described Day of Immunology events on 29 April.

The Day of Immunology was a remarkable success, exceeding our most ambitious expectations. We would like to take this opportunity to thank all participants of the National Immunological Societies and of EFIS for their enthusiastic support. Because of its enormous success, we are confident that the Day of Immunology not only should be repeated but also should be extended to become a global effort with the combined support of EFIS and other regional federations such as the Latin American Association of Immunology, the Federation of African Immunological Societies, the Federation of Immunological Societies of Asia-Oceania and all national societies that are members under our joint 'umbrella', the International Union of Immunological Societies.

\section{Stefan H E Kaufmann, Karen Bade \& Sabine Englich}

Max Planck Institute for Infection Biology, D-10117 Berlin, Germany.

e-mail:kaufmann@mpiib-berlin.mpg.de 